\title{
STRESS RESPONSE ANALYSIS OF CONCRETE PAVEMENT UNDER TIRE OF HEAVY VEHICLE
}

\author{
Veronika VALAŠKOVÁ ${ }^{1, *}$, Jozef VLČEK ${ }^{2}$ \\ ${ }^{1}$ Department of Structural Mechanics and Applied Mathematics, Faculty of Civil Engineering, \\ University of Žilina, Univerzitná 8215/1, 01026 Żilina, Slovakia. \\ 2 Department of Geotechnics, Faculty of Civil Engineering, University of Žilina, Univerzitná 8215/1, 010 \\ 26 Žilina, Slovakia. \\ * corresponding author: veronika.valaskova@fstav.uniza.sk.
}

\section{Abstract}

This article illustrates the applicability of the Finite Element Method (FEM) in the analysis of multi-layer concrete pavement systems subjected to tire loading of a heavy vehicle. For the purpose of simplifying the interaction of the interaction system, it is appropriate to divide the system into two separate independent subsystems, the vehicle and the pavement. For this reason, 2-dimensional interaction model of the contact vehicle-obstacle and 3-dimensional FEM model of the concrete pavement were created. A several constitutive material models, such as linear elastic model, are applied in the analysis to describe the behaviour of the pavement structure. The numerical results from the first computational model can be used as the input for the second calculation phase. The concrete pavement represents a standard pavement, which is used for the regular road structures in road engineering. FEM modelling of the pavement can be used for the direct estimation of the pavement response without performing time and cost expensive field experiments. Calculations were performed in software ADINA using FEM method.
\end{abstract}

\author{
Keywords: \\ Concrete pavement; \\ Finite element method; \\ Tire load; \\ Stress; \\ Displacement.
}

\section{Introduction}

The moving load effects represent the still actual problem, which is analysed in engineering practice in many workplaces around the world. The transport structures, such as pavements, are subjected to direct dynamic effect of the moving load. The main source of kinematic excitation is unevenness of the pavement. The reliability of transport structures loaded by the heavy traffic needs a detailed analysis using vehicle-ground interaction model [1]. The most important part of the process is to create a reliable calculation model and proper material parameters to describe the response of the ground to the vehicle loading [2].

Several computational numerical systems are available for the FEM dynamic analysis. Two models based on the dynamic theory of the moving load were created. For the purpose of simplifying the interaction of the interaction system, it is appropriate to divide the system into two separate independent subsystems, the vehicle passing over the obstacle and the pavement. A 2-dimensional interaction model of the vehicle passing over the obstacle and a 3-dimensional FEM model of the concrete pavement were created. Both of the computational models were created in the FEM software ADINA. FEM methods have been more widely used since computer calculations became part of the modelling tools.

\section{Numerical model of vehicle and pavement with obstacle}

One of the most important parts of the numerical simulation is the right selection of an appropriate interaction model. A 2-dimensional interaction model of the vehicle and the pavement with the obstacle were created. The half part model of the vehicle is usually used for 2D analyses. It is discrete model created with a combination of mass, spring and beam elements and it has finite 
degrees of freedom, which simplifies the solution in terms of mathematic formulation. The principal characteristic of the half part model is defined by three diagonal matrices, the mass $\{\boldsymbol{m}\}$, stiffness $\left\{\boldsymbol{k}_{i}\right\}$ and damping $\left\{\boldsymbol{b}_{i}\right\}$ matrices which were obtained on the basis of experimental measurements [3].

Matrices values for the lorry model were determined:

- $\left\{\boldsymbol{m}_{i}\right\}_{D}=\left\{m_{1}, I_{y 1}, m_{2}, m_{3}, I_{y 3}\right\}_{D}=\{11475 ; 31149 ; 455 ; 1070 ; 466\}_{D},\left[\mathrm{~kg}, \mathrm{~kg} \cdot \mathrm{m}^{2}\right]$,

- $\left\{k_{i}\right\}_{D}=\left\{k_{1}, k_{2}, k_{3}, k_{4}, k_{5}\right\}_{D}=\{143716.5 ; 761256 ; 1275300 ; 2511360 ; 2511360\}_{D},\left[\mathrm{~N} \cdot \mathrm{m}^{-1}\right]$,

- $\left\{\boldsymbol{b}_{i}\right\}_{D}=\left\{b_{1}, b_{2}, b_{3}, b_{4}, b_{5}\right\}_{D}=\{19228,260197,2746,5494,5494\}_{D},\left[\mathrm{~kg} \cdot \mathrm{s}^{-1}\right]$.

The natural frequencies were determined as:

- $\{f\}=\left\{f_{(1)} ; f_{(2)} ; f_{(3)} ; f_{(4)} ; f_{(5)}\right\}=\{1.13 ; 1.45 ; 8.89 ; 10.91 ; 11.71\}[\mathrm{Hz}]$.

The obstacle and the pavement are modelled as a rigid surface. Modelled pavement, including the obstacle, has a total length of $31.88 \mathrm{~m}$. The vehicle accelerates in the first section of a 15 meter length. The obstacle section is $1.88 \mathrm{~m}$ long. Its shape is in accordance with the recommendation for the dynamic tests of bridges and is also equal with the retarders for the pavements. The last section is $15 \mathrm{~m}$ long, and is used for deceleration of the vehicle (Fig. 1) [4].

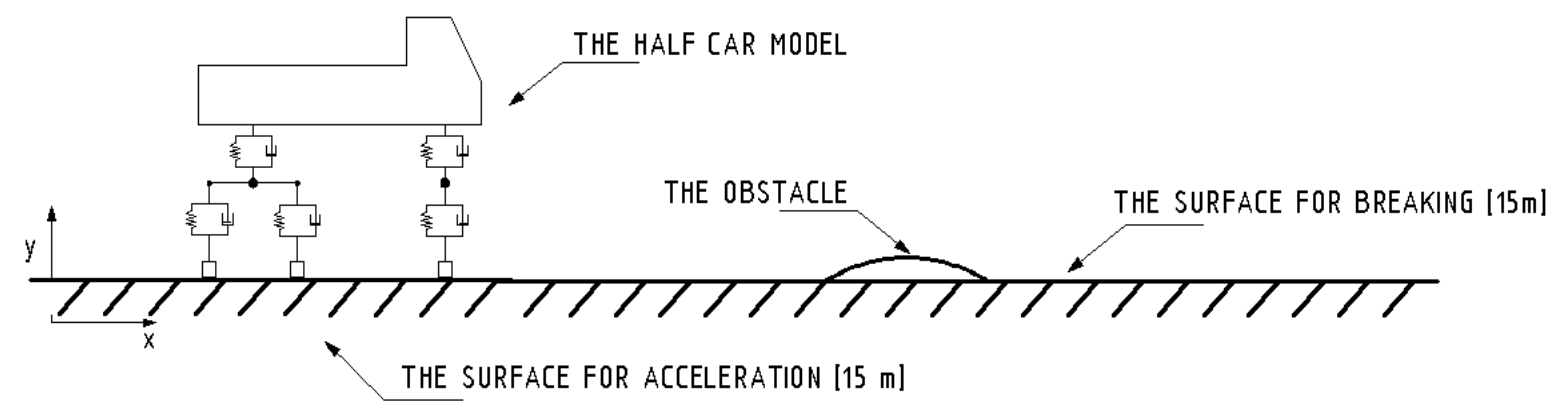

Fig. 1: Numerical model of the vehicle and the pavement with the obstacle.

The obstacle is defined as a function $h(x)$, where $h_{0}=0.06 \mathrm{~m}$ and $l_{0}=0.940 \mathrm{~m}$ (Fig. 2).

$h(x)=h_{0} \cdot \frac{1-\cos \left(\frac{2 \pi x}{I_{0}}\right)}{2}$.

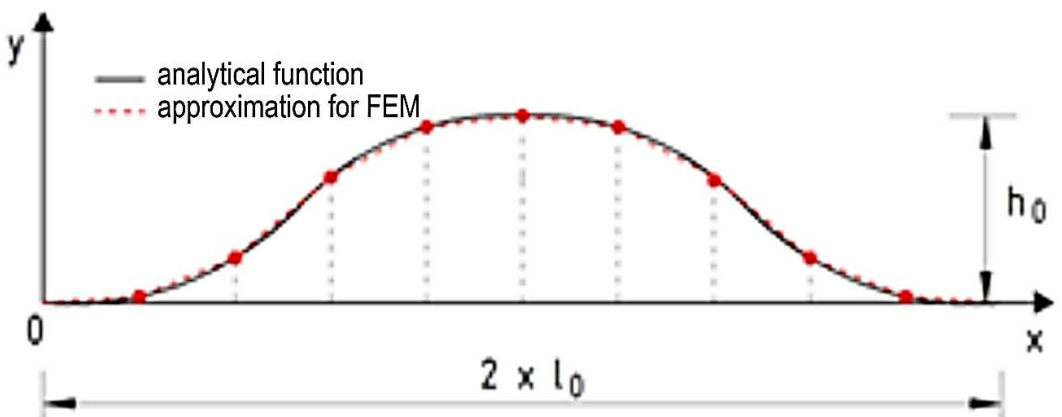

Fig. 2: The shape of the obstacle.

The half part model of the vehicle is moving along the pavement and the obstacle in constant speed of $40 \mathrm{~km} \cdot \mathrm{h}^{-1}$. Primary time step for the numerical simulation was $1 / 20 \mathrm{~s}$. The time step was then changed to $1 / 100 \mathrm{~s}$ when the vehicle passed the obstacle to obtain more accurate results. Resulting contact force for the front axle reached $8.32 \cdot 10^{4} \mathrm{~N}$. Subsequently, the contact force was distributed over idealized squared tire contact area with the dimensions $250 \times 200 \mathrm{~mm}$. The tire pressure was applied as a uniformly distributed load in the second step analysis with the intensity of $1664000 \mathrm{~Pa}$. As the last, contact load was applied on the concrete pavement surface to investigate the stress-strain state of the pavement system.

\section{Numerical model of concrete pavement}

A 3-dimensional numerical model of the concrete pavement was prepared. Material properties for particular construction layer were set considering the conventional concrete pavements. 
The 3-dimensional numerical model of the concrete pavement was modelled to investigate the stressstrain state of the pavement. The numerical model of the concrete pavement consists of the following layers with corresponding material properties (Table 1). Since the dynamic load inflicts very small deformation of the ground, it is necessary to use "dynamic" values of the modulus of elasticity $E$. The "dynamic" values are then higher than the "static" values.

Table 1: Composition of the layers of the concrete pavement.

\begin{tabular}{|c|c|c|c|c|c|}
\hline $\begin{array}{l}\text { Number of } \\
\text { layer }\end{array}$ & Material & Name & $\begin{array}{l}\text { Thickness } \\
\text { (mm) }\end{array}$ & $\begin{array}{c}\text { Modulus of } \\
\text { elasticity } E \\
\text { (MPa) }\end{array}$ & Poisson's ratio \\
\hline 1 & Cement concrete & $\mathrm{CC}$ & 260 & 37500 & 0.20 \\
\hline 2 & $\begin{array}{l}\text { Cement bound granular } \\
\text { mixture }\end{array}$ & CBGM & 220 & 2000 & 0.25 \\
\hline 3 & $\begin{array}{l}\text { Hydraulic road binder } \\
\text { bound granular mixture }\end{array}$ & HBBM & 320 & 350 & 0.30 \\
\hline 4 & Subgrade & $S$ & $\infty$ & 90 & 0.35 \\
\hline
\end{tabular}

For 3-dimensional numerical model of the concrete pavement, an adequate distributing loading area was selected. The area was chosen in accordance with the experimental measurements [5]. The dimensions of the load area were $250 \times 200 \mathrm{~mm}$. The numerical model of the pavement is plotted in Fig.3.

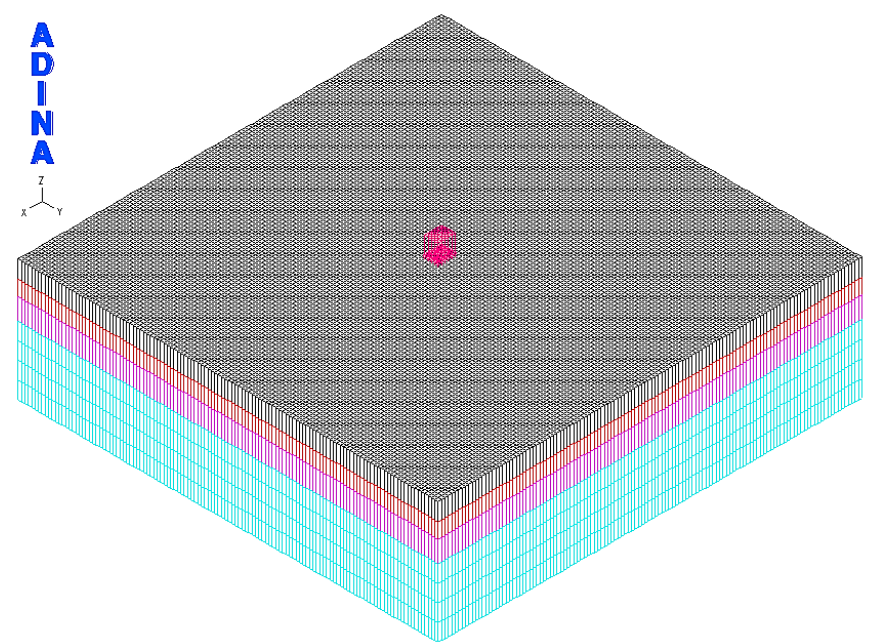

Fig. 3: The finite element model of the concrete pavement with subsoil layers.

The contact loading area has the dimension of $250 \mathrm{~mm}$ and $200 \mathrm{~mm}$ in the $x$ and $y$ direction. The overall dimensions of the subgrade were $6.2 \mathrm{~m}$ (X-direction) and $6.25 \mathrm{~m}$ ( $Y$-direction). The intensity of the uniform stress was $1664000 \mathrm{~Pa}$. The dimensions of the particular finite element were $5 \times 5 \mathrm{~mm}$. Each layer of the pavement was modelled separately with predefined material properties. The layers are modelled using 3D solid elements with the possibility of a check in mesh. The boundary conditions of the computational model are defined as fixed at the bottom and with the one degree of freedom in the appropriate direction $(X$ or $Y)$ on the vertical boundaries.

\section{Description of numerical procedure}

The numerical software ADINA is commercial engineering simulation software, which is used in engineering practice. It consists from four core modules and they are interconnected. Therefore, it is ideal for solve multiphysics problems. These include also dynamic interaction vehicle - pavement. A complete description of the numerical solution is found in [6]. 


\section{Results and discussion}

Following figures represent output of the numerical simulation for the stresses in $X$-, $Y$ - and $Z$-direction and also vertical displacement under load. The effective stresses calculated for particular layer also are shown.

\subsection{Vertical displacement}

Displacement propagation in the numerical model is plotted in Fig. 4 and 5 in the vertical planes parallel to the $X$-and $Y$-axis. The maximum value of deflection is $1.05 \cdot 10^{-5} \mathrm{~m}$. The area affected by the load is $2.45 \mathrm{~m}$ long in the $X$-direction and $2.525 \mathrm{~m}$ in the $Y$-direction from centre of the load.
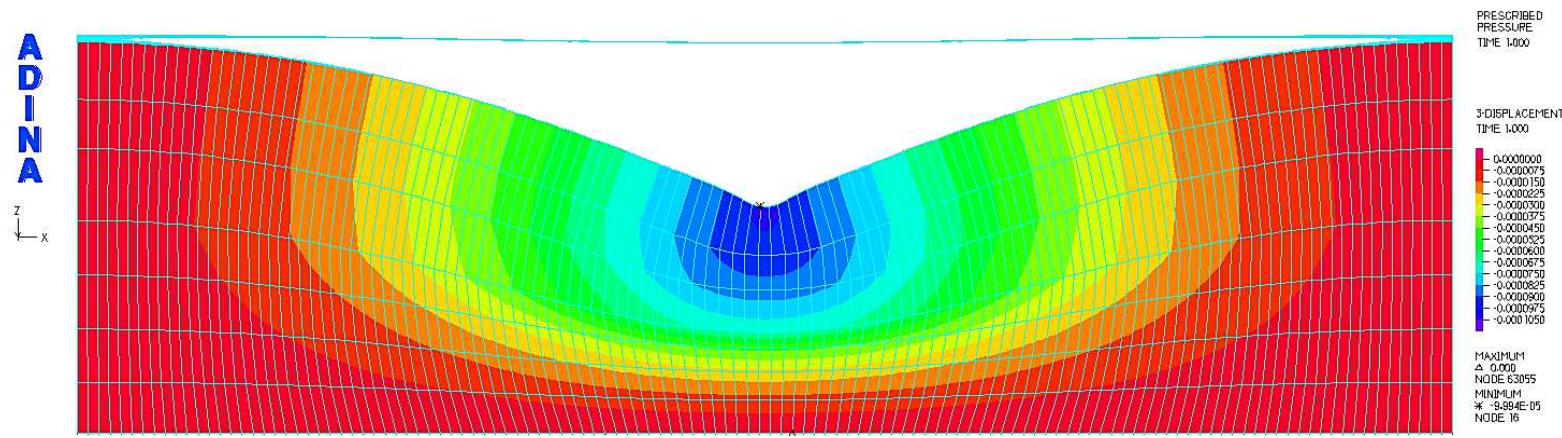

Fig. 4: Vertical displacements of the concrete pavement under the load, $X$-plane.

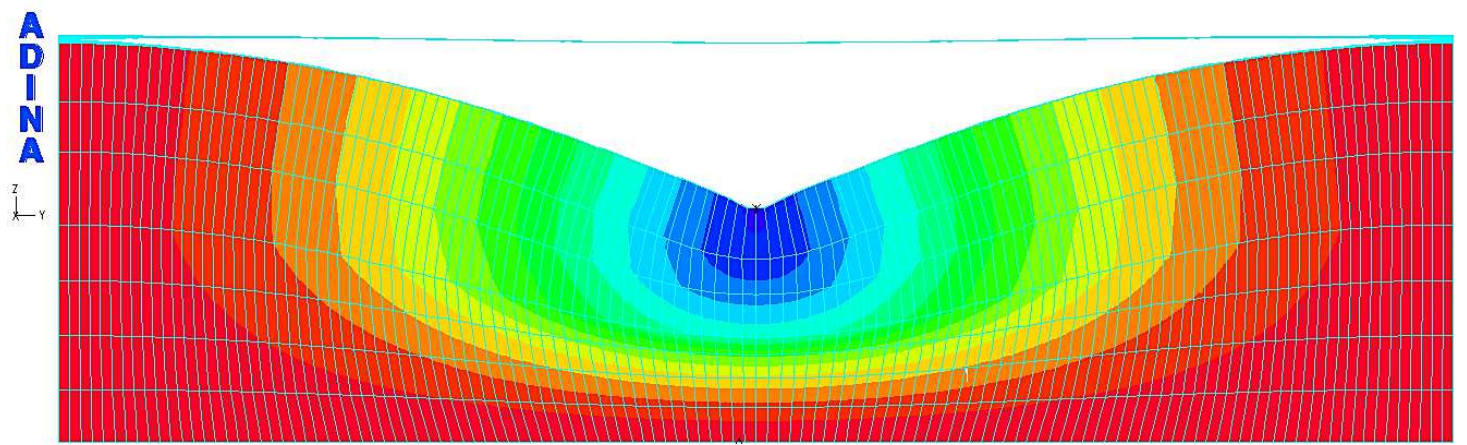

Fig. 5: Vertical displacements of the concrete pavement under the load, $Y$-plane

\subsection{Stresses}

Stress distribution in the numerical model in the $x$ plane is plotted in Fig. 6. The maximum horizontal stress $\sigma_{x}$ is $1.57 \mathrm{MPa}$ and the maximum horizontal stress $\sigma_{y}$ is $1.59 \mathrm{MPa}$. The maximum vertical stress $\sigma_{z}$ is $1.32 \mathrm{MPa}$. Peak values of the stresses are located in the first concrete layer with highest stiffness.

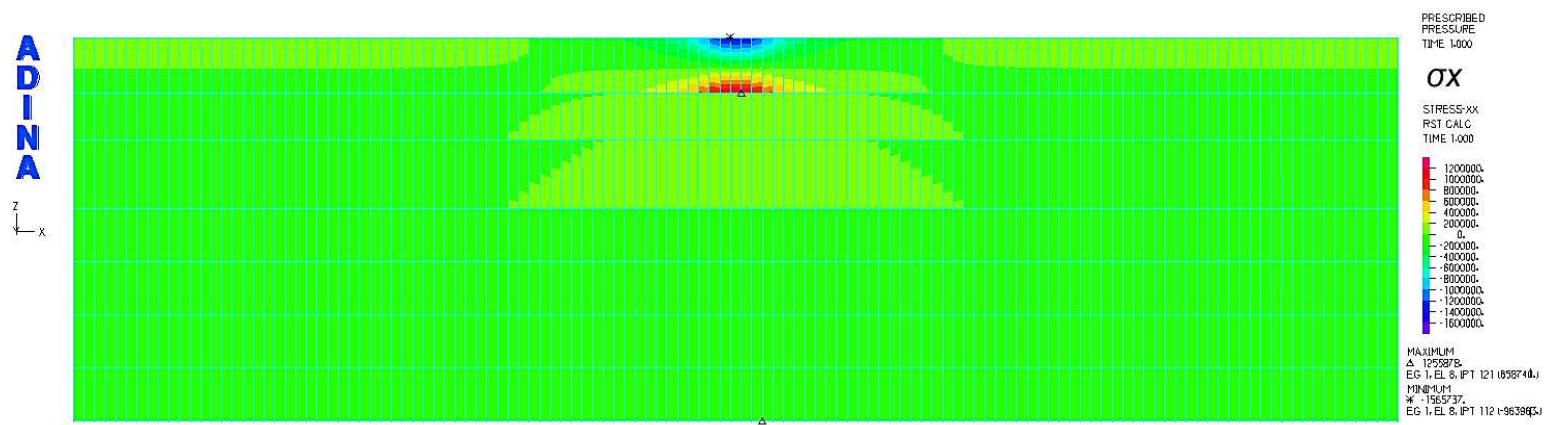



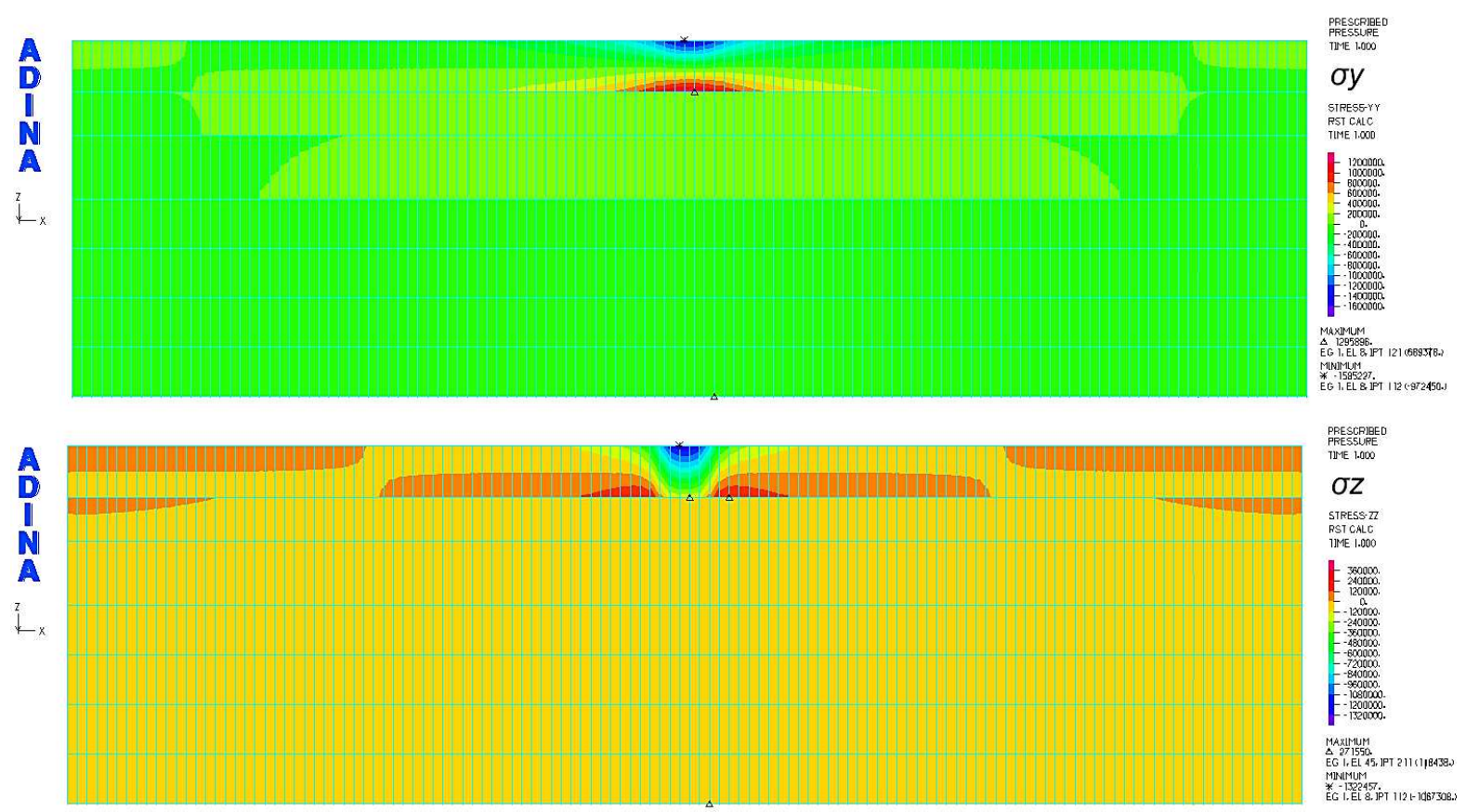

Fig. 6: Distribution of the horizontal stresses $\sigma_{x}$ and $\sigma_{y}$ and vertical stress $\sigma_{z}$ in the $X$-plane.

Similar results are also obtained in the $y$ plane where horizontal stress $\sigma_{x}$ and $\sigma_{y}$ reach the maximum value of $1.56 \mathrm{MPa}$ and $1.58 \mathrm{MPa}$ respectively. Vertical stress $\sigma_{z}$ is identical with the $X$-plane result.

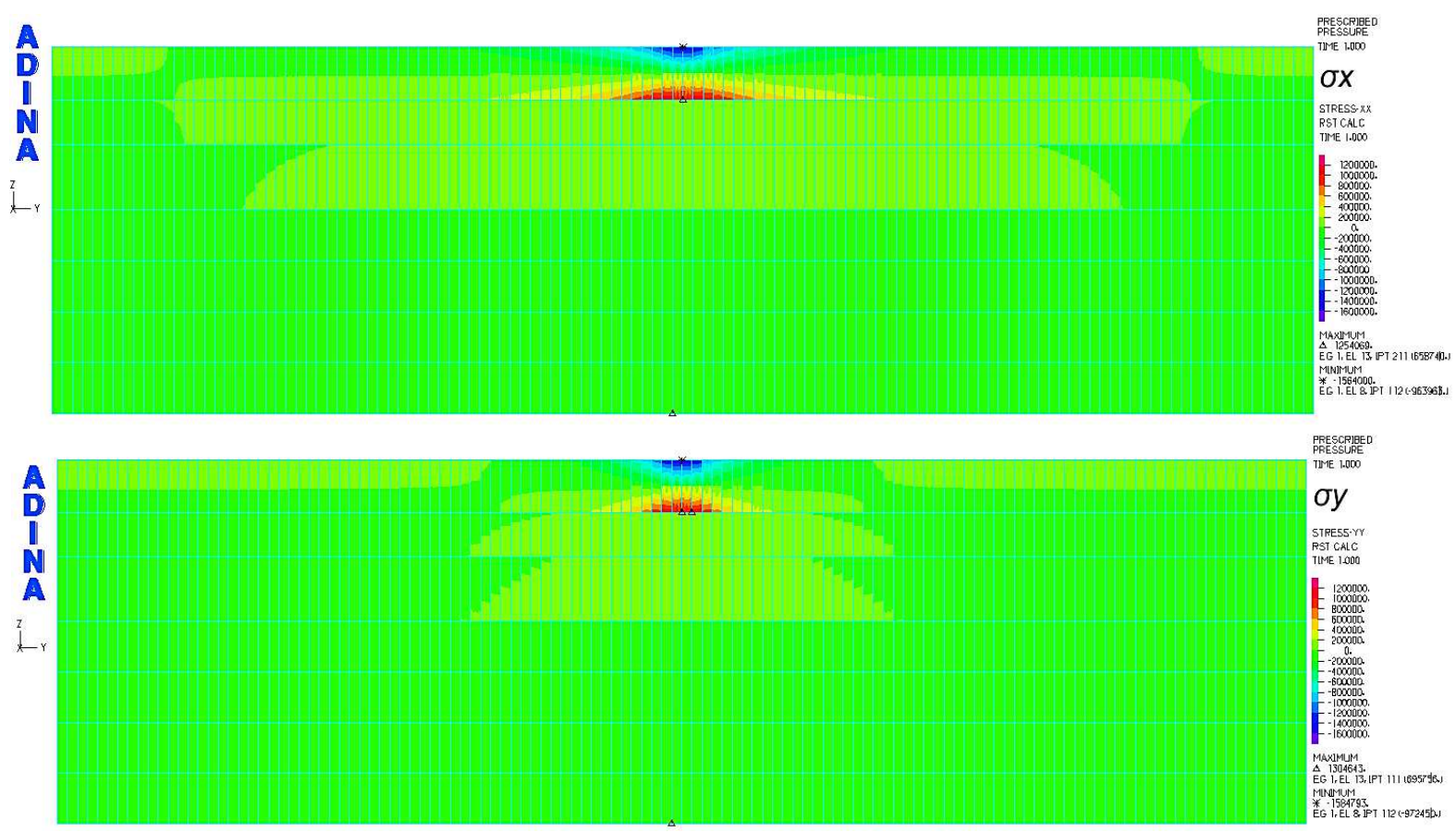




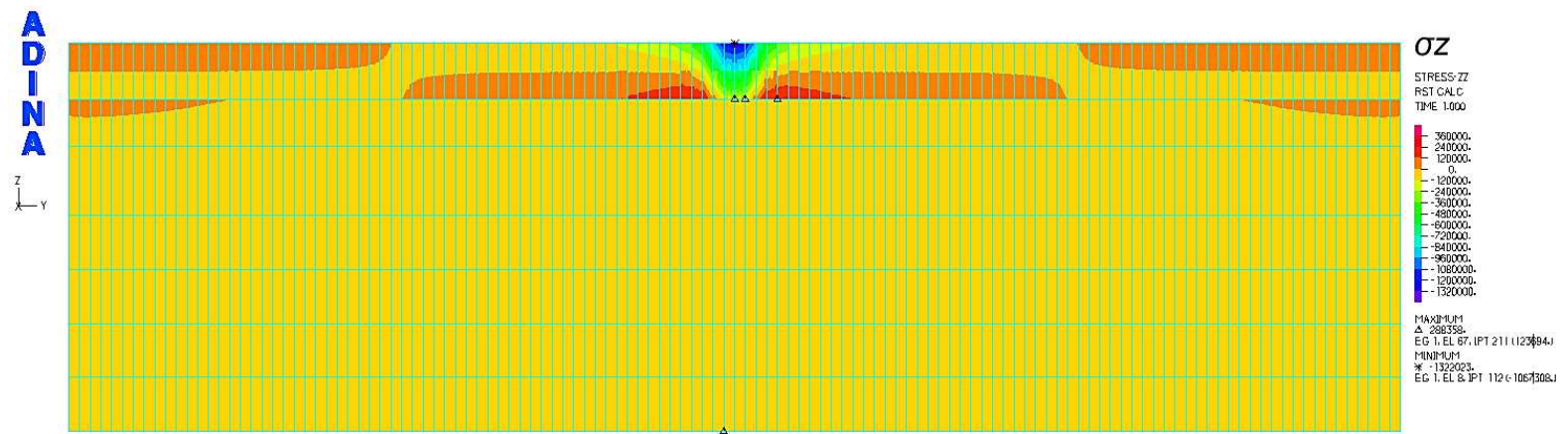

Fig. 7: Distribution of the horizontal stresses $\sigma_{x}$ and $\sigma_{y}$ and vertical stress $\sigma_{z}$ in the $Y$-plane.

\subsection{Effective stresses in individual construction layers}

Fig. 8 represents the effective stresses in the particular construction layers of the pavement. First layer is cement concrete, second layer is cement bound granular mixture, third layer is hydraulic road binder bound granular mixture and last layer is subgrade. In the first construction layer, the effective stress has a maximum value of $1.48 \mathrm{MPa}$. In the second construction layer, effective stress has a maximum value of $0.106 \mathrm{MPa}$. In the third construction layer, effective stress has a maximum value of $0.022 \mathrm{MPa}$ and in the subgrade layer the maximum effective stress is $0.008 \mathrm{MPa}$.
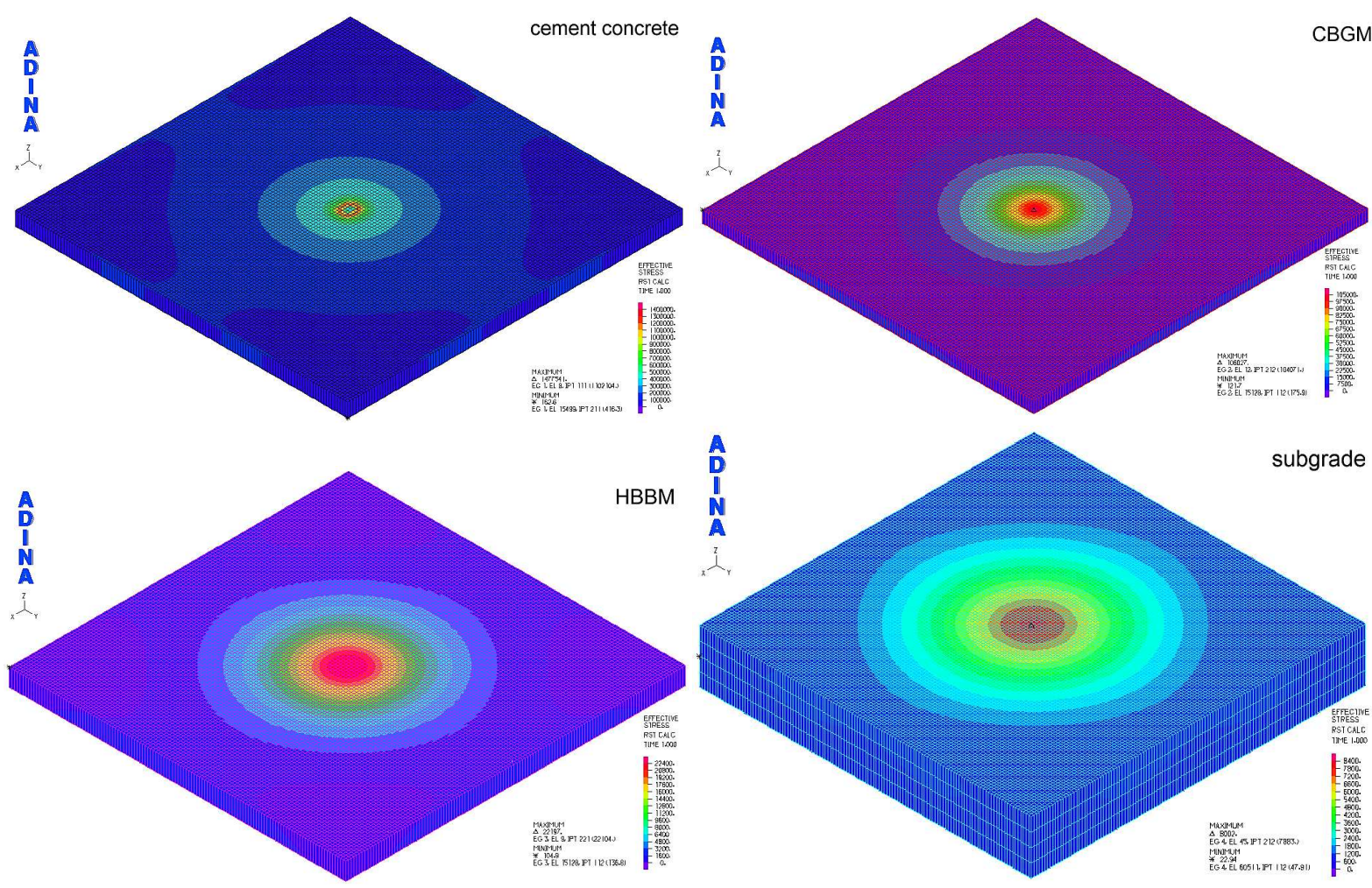

Fig. 8: Effective stresses in the particular construction layers.

\section{Conclusions}

This article demonstrates the applicability of FEM methods for the numerical simulation of the pavements. It is also focused on the synthesis of two separate models and the effectiveness of their use. The results of the first simulation are used as an input for the second stage. Stress analysis of the concrete pavement also shows differences between $x$ - and $y$-direction related to the uneven dimensions of the contact load area. Maximum values of the stresses are reached in the first concrete layer with the highest stiffness. Maximum deflection of the pavement surface is $1.05 \cdot 10^{-5} \mathrm{~m}$.

Further research will be aimed at the verification of the theoretical outputs of the computational simulations by the experimental way [7]. This will help to improve the design procedure of such pavements to achieve reliable and cost effective pavement structure design. 


\section{Acknowledgement}

This paper was supported by the Grant National Agency VEGA of the Slovak Republic (grant No. $1 / 0005 / 16)$.

\section{References}

[1] VALAŠKOVÁ, V.: The comparisons of computational models of pavement due to the dynamic load act. DYN - WIND 2017, MATEC Web of conference, 2017, DOI:10.1051/matecconf/2017107000.

[2] FRÝBA, L.: Vibration of Solids and Structures under Moving Loads. ACADEMIA, Praha, Nordhoff International Publishing, Groningen, 1972.

[3] MARTINICKÁ, I.: Calculation of Natural Frequencies and Vibration Shapes its own Computational Models of Vehicles Land. Communications and Tracks. Vol. 6 (1 - 2), 2010, pp. 41 - 50 (in Slovak).

[4] DANIEL, L'. - VALAŠKOVÁ, V. - KORTIŠ, J.: Numerical Simulation of Moving Vehicle across the Obstacle. Civil and Environmental Engineering, Vol. 10, Iss. 2, 2014, pp. $108-112$.

[5] VALAŠKOVÁ, V.: Dynamic effects of the vehicle on the pavement. Dissertation thesis, 2017 (in Slovak).

[6] ADINA R \& D. 2012 Theory and Modelling Guide. Volume I: ADINA. ADINA R \& D, Inc., Watertown, MA, USA, 2012.

[7] MELCER, J. - LAJČÁKOVÁ, G. - MARTINICKÁ, I. - KRÁLIK, J.: Dynamics of transport structures. EDIS, UNIZA, 2016 (in Slovak). 